DOI: https://doi.org/10.30749/2594-8261.v2n1p10-27

\title{
REPRESENTAÇÕES SOCIAIS E SOCIEDADES
}

\section{SOCIAL REPRESENTATIONS AND SOCIETIES}

\author{
Fábio Narduchi de Paula \\ Joaquim Humberto Coelho de Oliveiraii \\ Sonia Regina Mendes dos Santosiii
}

Resumo: Designadas "saber de senso comum", diferente do saber científico, mas de grande importância para a vida social e, por essa razão, dignas de atenção e de estudos, as representações sociais fornecem os elementos que permitem compreender o mundo, gerenciá-lo e, até mesmo, enfrentá-lo. É dentro do referencial teórico da Teoria das Representações Sociais, desenvolvida pelo teórico francês Serge Moscovici e demais autores da área, tais como Denise Jodelet, Jean Claude Abric e outros, que se embasará e se construirá o presente artigo, que tem como objetivo discorrer, por meio de pesquisa bibliográfica, acerca da teoria em voga, dada a importância das representações sociais nas comunicações e nas relações sociais. Conclui-se que, através da análise e da interpretação das representações sociais acerca de determinados objetos, tendo em vista o rico aporte teórico e metodológico da teoria, pode-se obter uma compreensão e uma explicação aprofundadas dos fenômenos sociais, haja vista as funções dessas representações sociais nas práticas em sociedade.

Palavras-chave: Representações sociais. Teoria das representações sociais. Fenômenos sociais.

\footnotetext{
' Mestre pelo Programa de Pós-Graduação em Humanidades, Culturas e Artes da Universidade do Grande Rio - UNIGRANRIO (Bolsista da Capes). Possui graduação (Licenciatura/Bacharelado) em Educação Física pela Universidade Estácio de Sá. Pós-graduado em Língua Portuguesa e em Supervisão e Orientação Educacional pela Universidade Cidade de São Paulo - UNICID. Atualmente, é docente das prefeituras de Nova Iguaçu e da cidade do Rio de Janeiro (funcionário público). Possui experiência na área de Educação Física, com ênfase em Educação Física Escolar.

ii Graduado em História pela Universidade Federal do Rio de Janeiro (1987), Mestre em Filosofia pela Pontifícia Universidade Católica do Rio de Janeiro (1992) e Doutor em Filosofia pela Pontifícia Universidade Católica do Rio de Janeiro (2000). Atualmente é professor do Programa de Mestrado e Doutorado Interdisciplinar: Humanidades, Culturas e Artes - UNIGRANRIO; professor na Escola de Ciências Sociais e Aplicadas - Curso de Bacharel em Direito e da Escola de Ciências da Saúde Curso de Psicologia da UNIGRANRIO; professor do Curso de Bacheral em Direito do UNIFESO.

iii Licenciada em Pedagogia pela Universidade Federal do Rio de Janeiro (1980) e graduada em Psicologia pela Universidade Federal Fluminense (1985), Mestre em Educação pela Universidade do Estado do Rio de Janeiro (1994), Doutora em Educação pela Universidade Federal do Rio de Janeiro (2000) e Pós-Doutorado na USP (2011). Atualmente é professora associada da Universidade do Estado do Rio de Janeiro/Faculdade de Educação da Baixada Fluminense.
} 
Abstract: Known as "knowledge of common sense", different from scientific knowledge, but of great importance to social life and, for that reason, worthy of attention and studies, social representations provide the elements that allow to understand the world, manage it and, until even, face it. It is within the theoretical reference of the theory of social representations, developed by the french theorist Serge Moscovici and other authors of the area, such as Denise Jodelet, Jean Claude Abric and others, who will be based and will build this article, which aims to run through bibliographical research on the Theory in vogue, given the importance of social representations in communications and social relations. It is concluded that, through the thorough analysis and interpretation of the social representations about certain objects, in view of the rich theoretical and methodological contribution of the theory, one can obtain an understanding and an in-depth explanation of the Social phenomena, view the functions of these social representations in the practices in society.

Keywords: Social representations. Theory of social representations. Social phenomena. 


\section{INTRODUÇÃO}

A análise das Representações Sociais (RSs) que certos grupos constroem acerca de determinados objetos sociais permite, em consequência, uma compreensão do universo de informações, de crenças, de normas e de expectativas que permeiam a prática cotidiana desses grupos, revelando, por sua vez, como essas práticas, envolvendo tais objetos, encontram-se compreendidas, identificadas, orientadas e justificadas ${ }^{1}$.

Trabalhando com a Teoria das Representações Sociais (TRSs), desenvolvida pelo teórico francês Serge Moscovici e demais autores da área, tais como Denise Jodelet, Jean Claude Abric e outros, tem-se um aporte teórico rico e adequado no que se refere ao trato com as impressões dos sujeitos pesquisados acerca de determinados objetos sociais, uma vez que tal teoria procura adentrar na cotidianidade dos sujeitos e filtrar as sínteses entre o cognitivo e o social, além de fornecer um conceito para se trabalhar com o pensamento social em seus processos, partindo do princípio de que existem formas diferentes e dinâmicas de se conhecer e de se comunicar, reguladas por diferentes objetivos (PEREIRA, 2016; SILVA, DIAS, PIMENTA, 2016).

De acordo com Silva, Dias e Pimenta (2016), encontra-se, atualmente, em plena expansão no Brasil, a Teoria das Representações Sociais, ampliando-se as áreas que têm aderido a esse referencial, dentre elas: Saúde, Educação e Serviço Social, crescendo os trabalhos de pesquisa envolvendo a mesma, podendo-se afirmar, até mesmo, que tal crescimento se deve "ao fato de que os estudos em representações sociais vêm mostrando o quanto essa noção e sua correlata base teórica permitem compreensão e explicação aprofundadas dos fenômenos sociais" (p.556).

É dentro desse referencial teórico que se embasará e se construirá o presente artigo, que tem como objetivo discorrer acerca da teoria em voga, haja vista a importância das representações sociais nas comunicações e nas relações sociais, visto serem elas designadas, tal como apontado por Almeida (2005), como

\footnotetext{
${ }^{1}$ Isto é, as quatro funções das representações sociais: a Função de Saber, a Função Identitária, a Função de Orientação e a Função Justificadora, que serão vistas, mais adiante, neste artigo.
} 
"saber de senso comum", "saber ingênuo" ou "natural", diferente do saber científico, mas de grande importância para a vida social e, por essa razão, dignas de atenção e de estudos, porquanto fornecem os elementos que permitem compreender o mundo, gerenciá-lo e, até mesmo, enfrentá-lo.

Dentro do amplo espectro teórico-metodológico oferecido pela Teoria das Representações Sociais e tendo em vista a sua importância no estudo de sociedades, urge que se pergunte, dentro do escopo deste artigo, quais são, afinal, as definições existentes acerca das representações sociais. Quais as suas funções? O que os estudos têm a dizer sobre a gênese e a dinâmica das mesmas? De que modo podem ser elas cientificamente tratadas e revelar, pois, importantes aspectos acerca das práticas sócias?

\section{A TEORIA DAS REPRESENTAÇÕES SOCIAIS NO ESTUDO DE SOCIEDADES}

Segundo Domingos Sobrinho (1998, p.118), a Teoria das Representações Sociais "se desenvolveu procurando estabelecer novas bases epistemológicas para a compreensão da relação Sujeito/Objeto", de maneira que Serge Moscovici, criticando os enfoques que concebiam tal relação de forma dicotomizada e descontextualizada, "procurou demonstrar que os processos através dos quais os sujeitos representam o mundo são extremamente dinâmicos e não comportam nenhum corte ou separação entre o universo interior e exterior aos mesmos".

Dessa maneira, quando se fala em representações sociais, parte-se de outras premissas, ou seja, considera-se que não existe um corte "dado" entre universo exterior e universo do indivíduo (ou do grupo), ou melhor, que sujeito e objeto não são totalmente heterogêneos em seu campo comum (MOSCOVICI, 1978).

Nessa perspectiva, afirma-se que "O objeto de uma representação faz parte de um contexto ativo e é concebido, pelo menos parcialmente, pela pessoa ou pelo grupo, enquanto prolongamento do seu comportamento" (DOMINGOS SOBRINHO, 1998, p.118) "e só existe para eles enquanto função dos meios e dos métodos que 
permitem conhecê-lo" (MOSCOVICl, 1978, p.48), sendo "a relação sujeito-objeto que determina o objeto em si mesmo" (DOMINGOS SOBRINHO, 1998, p.119).

Isso põe "em evidência a dinâmica relacional e simbólica através da qual os indivíduos entram em contato com o mundo exterior e o reproduzem à sua imagem e semelhança", permitindo, dessa forma, "compreender as ações humanas não somente como resultado de experiências acumuladas e de sistemas de disposições incorporados, mas também como produto da ação dos indivíduos sobre si mesmos e sobre o mundo exterior", como descrito por Domingos Sobrinho (1998, p.119).

Dessa maneira, pode-se afirmar que tal "hipótese, do abandono da dicotomia sujeito-objeto, confere um novo estatuto ao que se convencionou chamar de 'realidade objetiva', definida pelos componentes objetivos da situação e do objeto" (ABRIC, 1998, p.27), cabendo ressaltar, conforme aponta Moscovici (1978), que "a representação de um objeto é uma reapresentação diferente do objeto", de modo que "representar uma coisa, um estado, não consiste simplesmente em desdobrá-lo, repeti-lo ou reproduzi-lo; é reconstituí-lo, retocá-lo, modificar-lhe o texto" (p.58) e, nesse sentido, "todas as coisas são representações de alguma coisa" (p.64, grifo do autor), propondo-se, portanto, que

não existe uma realidade objetiva a priori, mas sim que toda realidade é representada, quer dizer, reapropriada pelo indivíduo ou pelo grupo, reconstruída no seu sistema cognitivo, integrada no seu sistema de valores, dependente de sua história e do contexto social e ideológico que o cerca.

E é esta realidade reapropriada e reestruturada que constitui, para o indivíduo ou grupo, a realidade mesma (ABRIC, 1998, p.27).

Toda representação é, por conseguinte, "uma forma de visão global e unitária de um objeto", bem como de um sujeito, de maneira que essa representação "reestrutura a realidade para permitir a integração das características objetivas do objeto, das experiências anteriores do sujeito e do seu sistema de atitudes e de normas", permitindo defini-la, pois, "como uma visão funcional do mundo, que, por sua vez, permite ao indivíduo ou ao grupo dar um sentido às suas condutas e compreender a realidade através de seu próprio sistema de referências", 
possibilitando a esse indivíduo adaptar-se e encontrar um lugar nessa realidade, conforme aponta Abric (1998, p.27-28).

Assim sendo, a representação não é, simplesmente, um reflexo da realidade, mas uma organização significante, dependente, ao mesmo tempo, de fatores contingentes, isto é, das circunstâncias ("natureza e limites da situação, contexto imediato, finalidade da situação"), "e de fatores mais globais que ultrapassam a situação em si mesma: contexto social e ideológico, lugar do indivíduo na organização social, história do indivíduo e do grupo, determinantes sociais, sistemas de valores", bem como apontado por Abric (1998, p.28)

Esclarece Moscovici (1978) que "representar um objeto é, ao mesmo tempo, conferir-lhe o status de um signo, é conhecê-lo, tornando-o significante. De um modo particular, dominamo-lo e interiorizamo-lo, fazemo-lo nosso" (pp.63-64, grifo do autor). Dessa maneira, "as representações sociais incitam-nos a preocupar-nos mais com as condutas imaginárias e simbólicas na existência ordinária das coletividades" (p.81) e, nesse aspecto, visto ser a conversação "uma atividade experimental das coletividades" (p.100), pode-se afirmar que "é nesse laboratório da sociedade que as combinações intelectuais são naturalmente selecionadas, antes de se cristalizarem em símbolos ou em ferramentas sociais" (p.101).

Estudando a psicanálise, uma teoria científica, Moscovici (1978) deixa patente que a mesma se modifica à medida que penetra na sociedade e é, pois, apropriada pelos diferentes grupos sociais, de maneira que: "Uma ciência do real torna-se, assim, uma ciência no real, dimensão quase física deste. Atingido esse estágio, sua evolução é assunto da Psicologia Social ${ }^{[\ldots] "}$ (p.18, grifos do autor) (DE PAULA, 2018, p.22).

Destarte, diferentes grupos sociais vão se lhe apropriando segundo suas visões políticas, suas posições sociais e seus níveis socioculturais, aponta Moscovici (1978), demonstrando, portanto, que o saber científico acaba por ser transformado em uma dimensão de senso comum, pelos diversos grupos: "A linguagem está repleta de expressões ou de vocábulos que têm sua origem na Psicanálise e que todos compreendem. A retórica religiosa, política, até mesmo econômica, não se 
dispensa de usar e abusar de tais expressões e vocábulos" (p.19). E assim, segundo o autor,

Insidiosa ou bruscamente, segundo os países, os regimes políticos ou as classes sociais, a psicanálise abandonou a esfera das idéias para ingressar na vida, nos pensamentos, nas condutas, nos costumes e no universo das conversações de grande número de indivíduos. Nós a vemos personificada pela fisionomia, os traços supostos da pessoa e os pormenores da biografia de Freud (MOSCOVICl, 1978, p.18, grifo do autor).

A história em quadrinhos, o romance, o filme e a anedota não se cansam de difundir expressões ou vocabulários que se originam na Psicanálise e que todos compreendem, de modo que, no que se refere ao conhecimento acerca desse objeto, "se recorta um modelo que, assimilado, ensinado, comunicado, repartido, dá forma à nossa realidade" e "confere à ciência de que provém as dimensões de um importante fato social e implanta-a na vida cotidiana da sociedade", tal como afirma Moscovici (1978, p.20).

Conforme salienta Wagner (1998): "A imaginação cultural dá realidade às coisas que habitam o mundo social" (p.6). "Se um grupo de pessoas se comporta como se a loucura fosse causada por possessão demoníaca [...], essa loucura se torna um fato em seu mundo" (p.11). "Agindo no sistema de representação, os membros de um grupo criam o objeto representado, dão-lhe significado e realidade" (p.11). Dessa forma,

a representação social é sempre uma unidade do que as pessoas pensam e do modo como fazem. Assim, uma representação é mais do que uma imagem estática de um objeto na mente das pessoas; ela compreende também seu comportamento e a prática interativa de um grupo. É ao mesmo tempo uma teoria sobre o conhecimento representado, assim como uma teoria sobre a construção do mundo (WAGNER, 1998, p.11).

Afirma Moscovici (1978, p.20-21): "As ciências inventam e propõem a maior parte dos objetos, conceitos, analogias e formas lógicas a que recorremos para fazer face às nossas tarefas econômicas, políticas ou intelectuais". Além do mais: "O que se impõe, a longo prazo, como dado imediato de nossos sentidos, de nosso 
entendimento, é, na verdade, um produto secundário, reelaborado, das pesquisas científicas"; e completa afirmando que: "Esse estado de coisas é irreversível. Corresponde a um imperativo prático" (MOSCOVICI, 1978, 21).

No processo de educação escolar, a maioria das pessoas nas sociedades modernas entra em contato com descobertas e teorias científicas. Dessa maneira, a ciência desempenha um importante papel como fonte de conhecimento do cotidiano, assim como uma autoridade para legitimar e justificar decisões cotidianas e posições ideológicas (Wagner, 1995b) (WAGNER, 1998, p.4).

Assim, "cada um aprende à sua maneira a manipular os conhecimentos científicos fora de seu âmbito próprio, impregna-se do conteúdo e do estilo do pensamento que eles representam" (MOSCOVICI, 1978, p.22), sendo "evidente que a propagação de uma ciência tem um caráter criador", de maneira que não devemos deixar escapar "o principal do fenômeno próprio de nossa cultura, que é a socialização de uma disciplina em seu todo e não, como se continua pretendendo, a vulgarização de algumas de suas partes" (p.24, grifos do autor).

Sendo assim, pode-se entender uma representação social como "uma forma de conhecimento socialmente elaborada e partilhada, tendo uma orientação prática ${ }^{2}$ e colaborando para a construção de uma realidade comum a um conjunto social" (JODELET, 1989, p. 36, tradução nossa), podendo ser entendida, além do mais, "como idéias, imagens" ${ }^{3}$, concepções e visões de mundo que os atores sociais possuem sobre a realidade, as quais estão vinculadas às práticas sociais" (MOREIRA; OLIVEIRA, 1998, p.xi-xii).

Quanto às quatro funções desempenhadas pelas representações sociais, tem-se: a Função de Saber (permitem compreender e explicar a realidade através

\footnotetext{
${ }^{2}$ Aqui, encontra-se uma de suas funções: a Função de Orientação.

${ }^{3}$ Cabendo ressaltar, aqui, que as representações sociais são entendidas como figura/significação, tal como em Moscovici (1978), "querendo com isso dizer que ela faz compreender a toda figura um sentido e a todo o sentido uma figura" (p.65). "As representações sociais apresentam-se, segundo Chamon (2014, p.306), 'sob dois aspectos: o da imagem (reprodução do real de maneira concreta) e o do conceito (abstração do sentido do real, ou melhor, significação que corresponde à imagem do real).' 'Toda representação é composta de figuras e de expressões socializadas. Conjuntamente, uma representação social é a organização de imagens e linguagem' (MOSCOVICl, 1978, p.25). Assim, podemos falar em 'conceitos e imagens ${ }^{,[. .]}$, como 'produtos da representação' (RANGEL, 2004, p.38)" (DE PAULA, 2018, p.32).
} 
de conhecimentos do dito "senso comum", ou seja, de um saber "ingênuo"); a Função Identitária (definem a identidade, além de permitirem a proteção das especificidades dos grupos, caracterizando-os, isto é, situando os indivíduos e os grupos dentro do campo social); a Função de Orientação (guiam os comportamentos e as práticas, orientando condutas $^{4}$ ); a Função Justificadora (permitem justificar, a posteriori, as tomadas de posição e os comportamentos, intervindo, pois, na avaliação da ação) (ABRIC, 1998).

Pode-se dizer que "cada grupo social elabora representações de acordo com a sua posição no conjunto da sociedade, representações essas que emergem de seus interesses específicos e da própria dinâmica da vida cotidiana" (MOREIRA; OLIVEIRA, 1998, p.xii). "São as representações sociais o que explica como um grupo se apropria de um objeto social e recria coletivamente seu significado, gerando, a priori, uma orientação para sua prática e, a posteriori, uma justificativa para suas ações" (CHAMON, 2014, p. 305).

Cumprem elas "uma função importante de regulação das relações entre diferentes atores sociais" (DOMINGOS SOBRINHO, 1998, p.119). "No final das contas, ela produz e determina os comportamentos ${ }^{5}$, pois define simultaneamente a natureza dos estímulos que nos cercam e nos provocam, e o significado das respostas a dar-Ihes" (MOSCOVICI, 1978, p.26), razão pela qual devam elas ser analisadas e interpretadas cientificamente, permitindo, assim, uma compreensão e uma explicação aprofundadas dos fenômenos sociais.

Em Rangel (2004, p.18), a representação social aparece "como forma de conhecimento dos objetos pelos sujeitos, tornando-os 'familiares' (menos estranhos), trazendo-os do 'exterior' para o 'universo interior', 'ancorando-os', sedimentando-os", de modo que "os objetos do conhecimento teórico são, em princípio, estranhos aos sujeitos [...] [e] a representação social é uma forma de conhecimento

\footnotetext{
${ }^{4}$ De acordo com Rangel (2004, p. 64), as representações influem "na constituição do real, na medida em que as percepções consubstanciam-se em idéias, expressas em conceitos e imagens, que podem determinar estigmas e preconceitos, orientando comportamentos, comunicações e relações humanas e sociais".

5 "As diferentes representações sobre o desenvolvimento humano construídas [por exemplo] em contextos sociais distintos terminam por servir de base para a construção de um modo diferente de ser criança, jovem, adulto ou velho em cada um desses espaços" (ALÉSSIO, 2005, p.95).
} 
pela qual os objetos tornam-se 'familiares' e são incorporados, assimilados". Assim, "o que era inalcançável tornou-se alcançável, inteligível e concreto" (MOSCOVICI, 1978, p.61), o que nos leva a entender uma RS "como forma de conhecimento prático" (RANGEL, 2004, p.22) "e compartilhado, potencialmente capaz de influir em visões e ações sociais" (RANGEL, 2004, p.51) (DE PAULA, 2018, p.25).

Conforme os autores da área, as representações sociais "constituem um saber: o do senso comum, o saber prático, que orienta a conduta dos indivíduos e sua comunicação" (SILVA; DIAS; PIMENTA, 2016, p. 991), de maneira que os sujeitos as constroem "para que as mesmas lhes possam servir de orientação, de um guia prático para a ação" (DOMINGOS SOBRINHO, 1998, p.119).

Assim, "as representações sociais construídas pelos sujeitos refletem em seus comportamentos e práticas sociais e no seu modo de pensar e de agir sobre o objeto fruto de suas representações", tal como nos afirma Mandú e Aguiar (2013, p.564), baseando-se em Moscovici (1978), tendo em vista, conforme Doise, Clemence e Lorenzi-Cioldi (1992), que a representação social não determina o comportamento, mas delimita o universo de possibilidades (DE PAULA, 2018, p.26).

As representações sociais permitem que o indivíduo construa uma identidade social, o que possibilita ao sujeito relacionar-se com seu grupo social e com outros grupos, por meio, respectivamente, de um sentimento de pertença e de alteridade e distinção, intervindo, dessa forma, na construção de identidades pessoais e sociais, no comportamento intra e intergrupal, nas práticas individuais e grupais, e em processos tais como a assimilação de conhecimento e as ações de resistência e de mudança social, servindo, assim, como guias de ação (MOSCOVICI, 1978; MANDÚ; AGUIAR, 2013), reforçando, ainda mais, a importância de seu estudo.

Elas são entendidas, por Moscovici (1978, p.41), como "entidades quase tangíveis", que "circulam, cruzam-se e se cristalizam incessantemente através de uma fala, um gesto, um encontro, em nosso universo cotidiano", de maneira tal que "A maioria das relações sociais estabelecidas, os objetos produzidos ou consumidos, as comunicações trocadas, delas estão impregnados”. E, por isso, 
"temos que encarar a representação social tanto na medida em que ela possui uma contextura psicológica autônoma como na medida em que é própria de nossa sociedade e de nossa cultura" (p.45, grifo do autor).

Para Santos (2005, p.34), "a representação social é um conjunto de conceitos articulados que tem origem nas práticas sociais e diversidades grupais cuja função é dar sentido à realidade social, produzir identidades, organizar as comunicações e orientar as condutas". Quanto à última, isto é, à sua Função de Orientação, ressalta-se que "Elas Guiam os Comportamentos e as Práticas", tal como sinaliza Abric (1998, p.29), funcionando, dessa maneira, como "um guia para a ação" (p.28).

Um outro aspecto ressaltado em estudos envolvendo representações sociais, como o nosso, refere-se à gênese e à dinâmica das mesmas, que clarifica importantes aspectos acerca de como elas são formadas e alteradas na dinâmica social (DE PAULA, 2018). Nesse sentido, Mandú e Aguiar (2013, p.563) afirmam, pautando-se em Moscovici (1978), que "a representação social de um objeto é formada através da reelaboração e adaptação do conhecimento, no contexto social do grupo, segundo a sua própria conveniência e de acordo com seus valores", sendo "elaborada através de dois processos, denominados de objetivação e ancoragem"

$\mathrm{Na}$ ancoragem, o objeto é inserido num sistema de pensamentos preexistentes, estabelecendo uma rede de significações em torno do mesmo, tal como afirmam Mandú e Aguiar (2013), fundamentando-se em Santos (2005), havendo, nesse processo, "a constituição de uma rede de significações em torno do objeto, atribuindo a este valores e práticas sociais pré-existentes; dessa forma, o objeto é associado a formas conhecidas e reconsiderado através delas" (MANDÚ; AGUIAR, 2013, p. 564).

Pela ancoragem, também denominada amarração ou ancoramento, "assimilam-se ou adaptam-se as novas informações aos conceitos e imagens já formados, consolidados e 'objetivados'” (RANGEL, 2004, p.31). "O objeto novo é

\footnotetext{
6 Tais processos indicam, importante ressaltar, "a maneira como o social transforma um conhecimento em representação e como esta representação transforma o social", segundo informa Jodelet (1992, p. 367) em Chamon (2014, p. 306).
} 
reajustado para que se enquadre na categoria conhecida adquirindo características dessa categoria" (SANTOS, 2005, p.33). Dessa forma, ancorar consiste em "classificar e dar nome a alguma coisa" (MOSCOVICI, 2003, p.61), num processo de categorização e de nomeação, o que permite situá-las diante dos valores sociais, conforme aponta Mandú e Aguiar (2013), baseando-se nos trabalhos de Moscovici (1978), de Jodelet (2005) e de Almeida (2005).

\begin{abstract}
Ela implica, portanto, em atribuição de sentido, isto é, "o enraizamento de uma representação inscreve-se numa rede de significados articulados e hierarquizados a partir de conhecimentos e valores preexistentes na cultura"[...]; em instrumentalização do saber, uma vez que "possibilita um valor funcional à representação, na medida em que se torna uma teoria de referência possibilitando a tradução e compreensão do mundo social"; e em enraizamento no sistema de pensamento, já que "as novas representações se inscrevem num sistema de representações preexistentes"; dessa forma, "o novo torna-se familiar ao mesmo tempo em que transforma o conhecimento anterior", de modo que "o sistema de pensamento preexistente ainda predomina e serve como referência para os mecanismos de classificação, comparação e de categorização do novo objeto", tal como nos aponta Santos (2005, p.33 apud DE PAULA, 2018, p.37).
\end{abstract}

Segundo Santos (2005), quando apareceram as primeiras informações sobre a AIDS, a imprensa logo chamou a "nova doença" de "câncer gay" ou "peste gay", visto que o fato de ter sido descoberta, inicialmente, em sujeitos gays, de causar a morte sem que se soubesse, de maneira exata, suas causas e de ser contagiosa levaram a imprensa a associar ao câncer (mortal) e à peste (mortal e contagiosa). "Um sentido foi atribuído ao novo objeto (AIDS) a partir de conhecimentos anteriores e um nome lhe foi atribuído" (p.33).

Pode-se entender a objetivação, do ponto de vista de Moscovici (1978), como o processo de tornar familiar algo desconhecido, por meio da tentativa de tornar concreto e palpável o conceito, para que seja mais bem entendido, fazendo, pois, "com que se torne real um esquema conceitual, com que se dê a uma imagem uma contrapartida material" (p.110). Corresponde ao processo de tornar concreto o que é abstrato, tal como esclarece Chamon (2014), substituindo o objeto pela sua imagem, melhor dizendo, "a imagem tornando-se o próprio objeto e não mais sua 
representação", sendo essa imagem "sempre uma simplificação, necessariamente deformada, do conceito que Ihe deu origem" (p.306).

Pela objetivação, dá-se a concretização, ou melhor, a "materialização" de conceitos em imagens (RANGEL, 2004). "Ela torna concreto o que é abstrato. Transforma um conceito em uma imagem ou em núcleo figurativo" (SANTOS, 2005, p.31). Assim, objetivar, segundo Moscovici (1978, p.111), "é reabsorver um excesso de significações materializando-as [...]. É também transplantar para o nível de observação o que era apenas inferência ou símbolo", esclarecendo que,

quando a percepção visual não dá a impressão de um saber, mas, sim, de um conhecimento imediato ou de um contato direto, ou melhor, quando as ideias já não são percebidas como produtos da atividade intelectual, mas como reflexos de algo que existe no exterior, podemos dizer que houve objetivação, isto é, uma "substituição do percebido pelo conhecido" (p.112) (DE PAULA, 2018, p.33).

Como exemplo, "o complexo da teoria psicanalítica deixa de ser uma hipótese teórica e passa, no senso comum, a ser um atributo real do outro. As idéias construídas em contextos específicos são percebidas como algo palpável, concreto e exterior ao sujeito" (SANTOS, 2005, p.31). Assim, "os elementos da língua científica passam para a linguagem corrente, onde obedecem a novas convenções. As palavras 'complexo', 'repressão', investidas de um novo poder, designam aqui manifestações ostensivas do real”. E, dessa maneira,

a Psicanálise, com o seu vocabulário, "serviria [...] para designar comportamentos psicológicos", tal como esclarece Moscovici (1978, pp.111-112, grifo do autor), de modo que "O hiato entre a ciência e o real se reduz, o que era específico de um conceito se propõe como propriedade da sua contrapartida no real", sendo "assim que cada um pode, em nossa sociedade, reconhecer os 'complexos' de um indivíduo como atributos da sua pessoa", sem "que, por outra parte, esse reconhecimento esteja obrigatoriamente associado à Psicanálise" (DE PAULA, 2018, p.34).

O fenômeno da violência, tal como salienta Aléssio (2005, p.81), "pode ser objetivado no espaço, por exemplo, quando se diz que um determinado local (a 
cidade) produz mais violência que outro (campo)", de maneira que "objetivar é tornar um conhecimento abstrato em algo concreto que seja próximo da realidade dos indivíduos", de modo que "os elementos que constituem a representação obtêm materialidade, além de que se formam expressões de uma realidade vista como natural".

\begin{abstract}
Assim, a coisificação, isto é, "a conversão de idéias em coisas localizadas fora da mentalidade individual [...] é prescrita como um cânone do senso comum do envolvimento cultural", conforme nos esclarece Moscovici (1978, pp.112-113), apoiando-se em Rose, e, nessa perspectiva, "a coisificação coletiva" constitui-se na "descrição mais concisa e reveladora da idéia cultural tratada em termos de suas fontes comportamentais". Dessa maneira, o autor conclui dizendo: "Como as pessoas conseguem projetar noções para um público, eis o problema básico da pesquisa empírica que relaciona a cultura e comportamento" (DE PAULA, 2018, p.35).
\end{abstract}

De Paula (2018), buscando explorar, em sua pesquisa, como estão ancoradas e objetivadas as representações sociais acerca do corpo nas aulas de Educação Física escolar ${ }^{7}$, acaba por concluir, por fontes imagéticas, que tais representações encontram-se, em suma, ancoradas em esferas, tais como: a relacional (nas relações que são estabelecidas com outro(s) corpo(s) e com elemento(s) do espaço), a étnica (na cor da pele dos corpos, ou melhor, em corpos com a tez de pele branca), a de gênero (na centralidade de gênero, especificamente, do gênero masculino), a dos materiais utilizados como recursos pedagógicos (no uso de materiais convencionais, particularmente, o elemento bola), a da esportivização (com trabalhos envolvendo modalidades esportivas como conteúdos, especialmente, o futebol), a da não diversificação de atividades-conteúdos; a da sistematização dessas aulas; e a do prazer.

Encontram-se tais representações objetivadas ${ }^{8}$, de modo respectivo, na forma de desenhos de alunos: em relação a outro(s) corpo(s) e a elemento(s) do

\footnotetext{
${ }^{7}$ De discentes (do $5^{\circ}$ e do $9^{\circ}$ ano do Ensino Fundamental) e de docentes atuantes nessa etapa da Educação Básica, por meio do Método Documentário e da Metodologia Qualiquantitativa do Discurso do Sujeito Coletivo.

${ }^{8}$ Ressaltando que, na objetivação, com a formação de uma imagem objetivada, ou melhor, com a representação imagética do objeto social por meio do estabelecimento de um núcleo figurativo, há uma naturalização da representação de tal objeto representado, limitando-o à imagem mental
} 
espaço; com a tez de pele branca; com o gênero masculino; relacionando-se com materiais convencionais, de modo particular, com o elemento bola; praticando esportes, mormente, o futebol; realizando somente uma atividade-conteúdo; desempenhando atividades sistematizadas; e com semblantes demonstrando satisfação, prazer (DE PAULA, 2018).

O autor relaciona tais ancoragens e objetivações encontradas, acerca de seu objeto de estudo, à prática cotidiana desses grupos ${ }^{9}$, acabando por concluir que tal prática, envolvendo os corpos nas aulas de Educação Física escolar, pela noção de habitus individual e coletivo do grupo produtor levantada na pesquisa,

encontra-se compreendida, identificada, orientada e justificada, com todas as suas implicações, na perspectiva relacional (outro(s) corpo(s) e elemento(s) do espaço), étnica (corpos com a tez de pele branca), de gênero (masculino), de utilização de materiais convencionais como recursos pedagógicos (elemento bola), da esportivização dessas aulas (futebol), da não diversificação de atividades-conteúdos, da sistematização dessas aulas e do prazer (DE PAULA, 2018, p.181).

Com isso, o autor acaba por deixar evidente a importância dos estudos em representações sociais, porquanto "permitem compreensão e explicação aprofundadas dos fenômenos sociais" (SILVA; DIAS; PIMENTA, 2016, p.556), razão pela qual se ampliam as áreas que têm aderido a esse referencial, como, por exemplo, Educação, Saúde e Serviço Social, e crescem os trabalhos de pesquisa envolvendo os estudos das mesmas (SILVA; DIAS; PIMENTA, 2016), que "passam a se constituir em um importante instrumento para a compreensão das realidades sociais, e de seus elementos cristalizados ou emergentes" (ALMEIDA, 2005, p.47).

efetivada, de maneira que se perde a consciência de que apenas se representa e essas representações acabam assumindo, pois, o caráter de verdade (MEDINA FILHO, 2013). E, assim, "A naturalização das noções lhes dá valor de realidades concretas, diretamente legíveis e utilizáveis na ação sobre o mundo e os outros" (JODELET, 2001, p.39 apud MEDINA FILHO, 2013, p.267). Com isso, "a construção mental do objeto social ganha valor de verdade e uma consistência que resiste às investidas de questionamento de sua veracidade ou adequação ao contexto atual" (MEDINA FILHO, 2013, p.268), mascarando "os valores através dos quais os grupos sociais constroem seus esquemas de pensamento, naturalizando-os e protegendo-os de qualquer possibilidade de questionamento" (idem).

${ }^{9}$ Para saber mais, vide a obra de De Paula (2018). 


\section{CONSIDERAÇÕES FINAIS}

Ressalta-se, para fins conclusivos, que a maneira como os indivíduos adquirem o conhecimento do senso comum e a quantidade expressiva de informações, de valores, de crenças e de expectativas que esse tipo de conhecimento incorpora e acumula deveriam ser mais considerados (RANGEL, 2004) em estudos de sociedades, na medida em que oferecem valiosas indicações acerca das práticas sociais, tendo em vista que "cada grupo tem um universo de opinião particular" (MOSCOVICl, 1978, p.32) e conhecê-lo implica, portanto, agir.

O agir, pela busca de novos significados, de novos sentidos e, até mesmo, de novas práticas, a partir das informações advindas das representações e reveladas por elas, é, por meio de estudos envolvendo representações sociais, de capital importância, encarando o ser humano como um "ser de relação e de símbolo" (LE BRETON, 2011, p. 290), por conseguinte, "construtivo e não predeterminado, ou seja, ele elabora, reelabora e altera os significados das coisas com as quais interage no ambiente social" (SILVA; DIAS; PIMENTA, 2014, p. 552).

Assim sendo, através da análise e da interpretação das representações sociais acerca de determinados objetos, tendo em vista o rico aporte teórico e metodológico da Teoria das Representações Sociais, pode-se obter uma compreensão e uma explicação aprofundadas dos fenômenos sociais, haja vista as funções dessas representações sociais nas práticas em sociedade.

\section{REFERÊNCIAS}

ABRIC, J. C. A abordagem estrutural das representações sociais. In: MOREIRA, A. S. P.; OLIVEIRA, D. C. (Orgs.). Estudos interdisciplinares de representação social. Goiânia: AB, 1998.

ALÉSSIO, Renata Lira dos Santos. Desenvolvimento humano e violência na zona rural. In: SANTOS, Maria de Fátima de Souza; ALMEIDA, Leda Maria de. (Org.). Diálogos com a teoria da representação social. Recife: Ed. Universitária da UFPE, 2005.

ALMEIDA, Geraldo José de. As representações sociais, o imaginário e a construção social da realidade. In: SANTOS, Maria de Fátima de Souza; ALMEIDA, Leda Maria 
de. (Org.). Diálogos com a teoria da representação social. Recife: Ed. Universitária da UFPE, 2005.

CHAMON, E.M.Q.O. Representações sociais da formação docente em estudantes e professores da Educação Básica. Revista Quadrimestral da Associação Brasileira de Psicologia Escolar e Educacional, São Paulo, v. 18, n. 2, maio/ago. 2014.

DE PAULA, Fábio Narduchi. As representações sociais de alunos e de professores acerca do corpo nas aulas de educação física escolar. 2018. $200 f$. Dissertação (Mestrado) - Escola de Educação, Ciências, Letras, Artes e Humanidades, Universidade do Grande Rio "Prof. José de Souza Herdy" (Unigranrio), Duque de Caxias, 2018.

DOMINGOS SOBRINHO, M. "Habitus" e representações sociais: questões para o estudo de identidades coletivas. In: MOREIRA, A. S. P.; OLIVEIRA, D. C. (Org.). Estudos interdisciplinares de representação social. Goiânia: AB, 1998.

JODELET, D. Représentations sociales: um domaine em expansion. In: JODELET, D. (Ed.). Lés représentations sociales. Paris: PUF, 1989.

LE BRETON, David. Antropologia do corpo e modernidade. Tradução Fábio dos Santos Creder Lopes. Petrópolis, RJ: Vozes, 2011.

MANDÚ, T. M. C; AGUIAR, M. C. C. A formação inicial no curso de pedagogia: representações, caminhos e perspectivas dos estudantes. Educação Temática Digital, Campinas (SP), v. 15, n.3, p.560-577, 2013.

MEDINA FILHO, A. L. Importância das imagens na metodologia de pesquisa em psicologia social. Psicologia \& Sociedade, v. 25, n. 2, p. 263-271, 2013.

MOREIRA, A. S. P.; OLIVEIRA, D. C. Apresentação. In: MOREIRA, A. S. P.; OLIVEIRA, D. C. (Org.). Estudos interdisciplinares de representação social. Goiânia: AB, 1998.

MOSCOVICI, S. A Representação Social da Psicanálise. Rio de Janeiro: Zahar, 1978.

. Representações sociais: investigações em psicologia social. Petrópolis, RJ: Vozes, 2003.

PEREIRA, Alexandre de Jesus. Horta escolar: uma ferramenta interdisciplinar de educação ambiental e de desenvolvimento sustentável. 2016. 69 f. Dissertação (Mestrado em Desenvolvimento Local) - Centro Universitário Augusto Motta, Rio de Janeiro, 2016. 
RANGEL, Mary. A pesquisa de representação social como forma de enfrentamento de problemas socioeducacionais. Aparecida, SP: Idéias e Letras, 2004.

SANTOS, Maria de Fátima de Souza. A teoria das representações sociais. In: SANTOS, Maria de Fátima de Souza; ALMEIDA, Leda Maria de. (Org.). Diálogos com a teoria da representação social. Recife: Ed. Universitária da UFPE, 2005.

SILVA, Rejane Dias da; DIAS, Adelaide Alves; PIMENTA, S. A. Profissionalidade e formação docente: representações sociais de professores. Rev. Diálogo Educ., Curitiba, v. 16, n. 50, p. 987-1007, out./dez. 2016.

WAGNER, Wolfgang. Sócio-gênese e características das representações sociais. In: MOREIRA, A. S. P.; OLIVEIRA, D. C. (Org.). Estudos interdisciplinares de representação social. Goiânia: $A B, 1998$. 